\section{Biosynthesis of Prostaglandins 1}

MARTIN E. HEMLER and WILLIAM E.M. LANDS, Department of Biological Chemistry, The University of Michigan, Ann Arbor, MI 48109

\section{ABSTRACT}

Highly purified cyclooxygenase from sheep vesicular glands is stimulated by the presence of protoporphyrin IX compounds. This stimulation may be due to the conversion of an apoenzyme to the holoenzyme, and full activity is achieved when half of the enzyme subunits (70,000 daltons) bind heme. Also, onehalf of the subunits appear to contain non-heme iron. The apparent molecular weight of the holoenzyme is approximately 300,000 daltons and is compatible with a complex of four 70,000 dalton subunits. Thus, we suggest that heme and non-heme iron may be attached to different 70,000 daltons subunits that make up an $A_{2} B_{2}$-type of peptide chain arrangement.

\section{INTRODUCTION}

In the overall scheme of prostaglandin formation, free fatty acid is first converted to an endoperoxide, PGG, which is then converted to other biologically active products including prostaglandins, thromboxanes, and other oxidized derivatives. The fatty acid cyclooxygenase which adds two molecules of $\mathrm{O}_{2}$ to substrate fatty acid and forms the cyclic endoperoxide is a unique dioxygenase of central importance. A monooxygenase would utilize $\mathrm{O}_{2}$ by adding one oxygen atom to the substrate and reducing the other oxygen to water. A dioxygenase commonly adds both oxygen atoms of $\mathrm{O}_{2}$ to substrate. The cyclooxygenase, however, may be regarded as a bis-dioxygenase since it adds two $\mathrm{O}_{2}$ molecules to the substrate fatty acid.

This unique enzyme has many regulatory features including hydroperoxide activation (1), glutathione peroxidase inhibition $(2,3)$, reaction-catalyzed inactivation (2), and inhibition by antiinflammatory drugs (4). The enzyme must have some complicated mechanistic features if it is to create the proposed interactions of oxygen, activator, substrate and enzyme (5). To facilitate our understanding of

\footnotetext{
${ }^{1}$ This work was presented at the 1976 Fall Meeting of The American Oil Chemists' Society at which M.E.H. was an Honored Student Awardee.
}

this complex enzyme, some properties of the purified cyclooxygenase including interactions of subunits and prosthetic groups were examined.

\section{MATERIALS AND METHODS}

\section{Materials}

Sheep vesicular glands were generously donated by Upjohn Co., Kalamazoo, MI and the Flurbiprofen-Sepharose was prepared by $\mathrm{Dr}$. W.L. Smith (6). Tween-40, DEAE cellulose, sodium diethyldithiocarbamate, hemoglobin, myoglobin, bovine serum albumin, catalase, phosphorylase a, and hemin were purchased from Sigma Chemical Co., St. Louis, MO. Lactate dehydrogenase was purchased from Calbiochem, (Elk Grove Village, IL,) and all other protein standards and the Blue Dextran 2000 were purchased from Pharmacia, Piscataway, NJ, Ampholine carrier electrolytes from LKB, Rockville, MD, adenosine- $5^{\prime}$-diphosphate from P-L Biochemicals, Inc., Milwaukee, WI, and flufenamic acid from Aldrich Chemical Co., Milwaukee, WI.

\section{Experimental Procedures}

Purified cycloxygenase was obtained by following the procedures of Hemler et al. (7) in which the final enzyme material was chromatographed on Biogel P-30 or Sephadex G-200, or used immediately after isoelectric focusing without further chromatography.

To perform isoelectric focusing in a narrow range of $\mathrm{pH}$ values, the procedures described earlier (7) for focusing at pH 5 to 8 were scaled up using a LKB 8101 Ampholine Column (440 $\mathrm{ml})$. Then the active enzyme fractions $(\sim 60$ $\mathrm{mls})$ plus additional ampholyte $(0.14 \mathrm{ml}, \mathrm{pH}$ 5-8) were refocused in a LKB $8101(110 \mathrm{ml})$ column. A continuous glycerol density gradient was prepared from: (a) a heavy solution that contained $9 \mathrm{ml}$ of glycerol and $45 \mathrm{ml}$ of enzyme solution and (b) a light solution that contained $15 \mathrm{ml}$ of enzyme solution and $39 \mathrm{ml}$ of $0.5 \mathrm{mM}$ tris $\mathrm{HC1}(\mathrm{pH} 8.5)$. After about $40 \mathrm{hr}$ of focusing, $2 \mathrm{ml}$ fractions were collected and the pH was determined using a Radiometer Model PHM-28 pH meter.

Heme-binding experiments consisted of incubation of purified cyclooxygenase with a threefold and tenfold molar excess of hematin per 


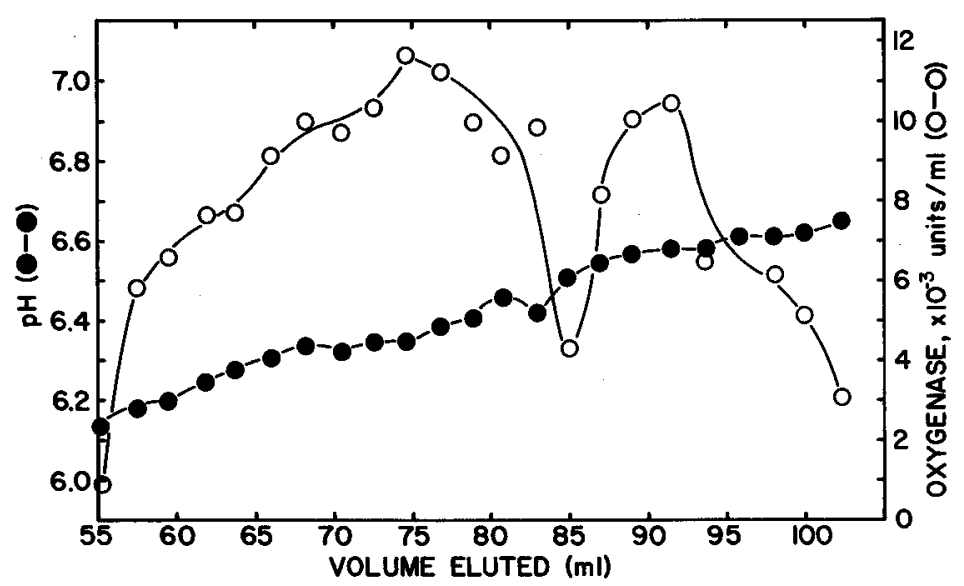

FIG. 1 Narrow range isoelectric focusing. After isoelectric focusing as described in Methods, fractions were collected and assayed for oxygenase activity $(0-0)$ and $\mathrm{pH}(\bullet-\bullet)$.

70,000-dalton subunit for $1 \mathrm{hr}$ at $0 \mathrm{C}$. The mixtures were then chromatographed on Biogel $\mathrm{P}-30(1 \times 38 \mathrm{~cm})$ at $2 \mathrm{ml} / \mathrm{hr}$ at $4 \mathrm{C}$ in $0.02 \mathrm{M}$ sodium phosphate (pH 7.0) containing $20 \%$ ethylene glycol. Fractions of $\sim 1.2 \mathrm{ml}$ were collected and analyzed for iron, heme, protein, and enzyme activity.

\section{Molecular Weight Determinations}

The molecular weight of cyclooxygenase subunits was determined using the SDS gel electrophoresis system described earlier (7). Protein standards of known molecular weight were included with the purified cyclooxygenase, the stained gels were scanned at $540 \mathrm{~nm}$, and the position of each band was calculated relative to the bromphenol blue tracking dye. The identity of the cyclooxygenase band was verified since it was located in the region radio-labeled by $\left[{ }^{3} \mathrm{H}\right]$ acetylsalicylate as previously described.

The molecular weight of active cyclooxygenase holoenzyme was estimated from gel filtration on Biogel P-300 $(2.5 \times 82.5 \mathrm{~cm})$ and Biogel A - $1.5 \mathrm{~m}(2.5 \times 44 \mathrm{~cm})$, each equilibrated with $0.1 \mathrm{M}$ tris-chloride ( $\mathrm{pH} \mathrm{8.0)}$ containing $20 \%$ ethylene glycol, $0.2 \%$ Tween-40 and $5 \mathrm{mM}$ diethyldithiocarbamate. For both columns, Blue Dextran-2000 was used to calculate the void volume, and the enzyme fractions utilized had been purified up to and including the isoelectric focusing procedure.

\section{Analytical Procedures}

Iron was measured using a model AA-5 Varian Techtron atomic absorption spectrometer as described earlier (7). Protein was determined by the method of Lowry et al. (8) or by quantitative scanning of SDS gels (7). Spectra of the purified enzyme were recorded on a
Cary 118 recording spectrophotometer and heme was quantitated by a modification (7) of the reduced pyridine hemochrome method of Falk (9).

Standard conditions for the assay of cyclooxygenase consisted of polarographic measurement of oxygen consumption $(6,10)$ in reaction vessels containing $100 \mu \mathrm{M}$ arachidonic acid, 0.5 $\mu \mathrm{M}$ bovine hemoglobin or $0.4 \mu \mathrm{M}$ hematin, and $0.67 \mathrm{mM}$ phenol in a total volume of $3 \mathrm{ml}$ of $0.1 \mathrm{M}$ tris-chloride ( $\mathrm{pH}$ 8.5). Reactions were initiated by the addition of enzyme, and one unit of activity is defined as the amount of enzyme which will catalyze the uptake of $1 \mathrm{nmole}$ of oxygen $/ \mathrm{min}$ at $30 \mathrm{C}$.

\section{RESULTS AND DISCUSSION}

\section{Isoelectric Focusing}

Rome and Lands (10) previously had solubilized membrane-bound cyclooxygenase with the nonionic detergent, Tween-40, fractionated with ammonium sulfate, chromatographed on an ion exchange resin and achieved 60-fold purification. Further purification was achieved by affinity chromatography using a Flurbiprofen-Sepharose column (6) and the active fractions were then pooled and subjected to preparative isoelectric focusing (7). Results from isoelectric focusing and immunoelectrophoresis (11) experiments had suggested the possibility of multiple forms of the enzyme. Further support for this hypothesis was obtained upon performing a high resolution isoelectric focusing experiment in the range of $\mathrm{pH}$ 6-7. As shown in Figure 1, there appeared to be separation of enzyme into two distinguishable peaks with the approximate isoelectric points of $\mathrm{pH}$ 6.35 and 6.58 , thus supporting the possibility 


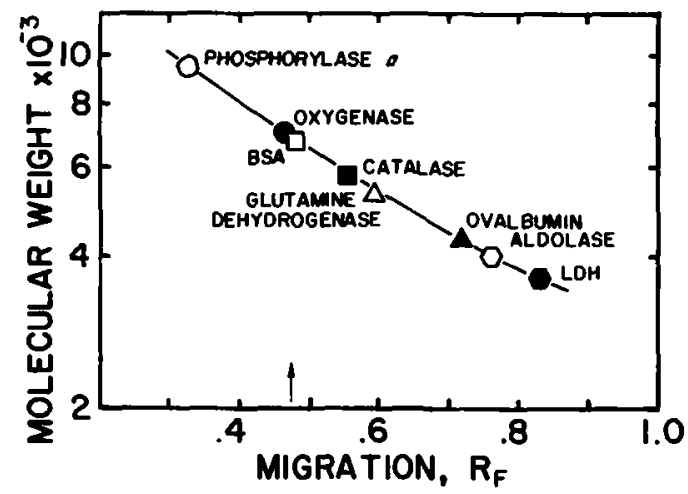

FIG. 2. Determination of molecular weight of cyclooxygenase subunits.

of two different isozymes. However, the enzyme fractions of $\mathrm{pI} \sim 6.3$ and $\mathrm{pI} \sim 6.5 \mathrm{had}$ similar specific activities $(\sim 46,000$ units $/ \mathrm{mg})$ and visible spectra (trace peak at $412 \mathrm{~nm}$ ). Also, the relative reactivities of the substrates, arachidonic acid and eicosatrienoic acid, were the same with both forms $\left(\frac{20: 3}{20: 4}=1.5\right)$, and SDS gel electrophoresis showed that each form was composed entirely of 70,000 dalton subunits (See Fig. 2). The difference in isoelectric point may reflect an apparent charge heterogeneity, but varied amounts of bound lipid or detergent may have also contributed to multiple peak formation.

\section{Molecular Weight}

After isoelectric focusing and gel filtration, the enzyme preparation had a high degree of homogeneity as indicated by a single band upon SDS gel electrophoresis. The subunit molecular weight was determined using protein standards as shown in Figure 2. A value of 70,000 daltons/subunit was obtained in either the presence or absence of $\beta$-mercaptoethanol, reaffirming that if there are multiple subunits, they are not linked by disulfide bonds. An estimated molecular weight for the active holoenzyme was then determined from gel filtration experiments on Biogel P-300 and Biogel A-1.5 m. For each column, calculations of $v_{c} / v_{0}$ were consistent with a molecular weight of 300,000 daltons, similar to that recently reported for the bovine enzyme (12). This value may be artificially high due to the presence of $0.2 \%$ Tween 40 in the column buffers, but it is consistent with a tetrameric arrangement of the 70,000 dalton subunits.

\section{The Role of Heme}

Previous work had shown that hematin could bind and activate cyclooxygenase which

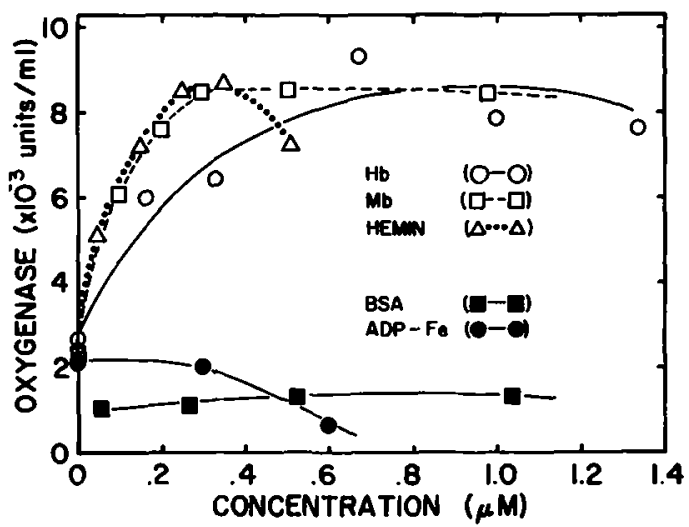

FIG. 3. Heme stimulation of cyclooxygenase activity. Varied amounts of each material were included in the otherwise heme-free standard assay mixture as indicated. For the protoheme compounds, the $x$-axis represents the concentration of total heme in each solution.

had retained only a trace of native heme after purification (7). The enzyme which forms prostaglandin in bovine seminal vesicles also seemed to be stimulated by heme compounds $(12,13)$, and it might also have had some heme present after purification (12). The ability of several protoheme compounds to stimulate the purified sheep cyclooxygenase was examined in detail as shown in Figure 3. Upon adding increasing amounts of free hemin, or bound heme as myoglobin or hemoglobin, the basal level of activity of the purified apoenzyme was increased several fold. In control experiments, ADP-iron, a known catalyst of nonenzymatic fatty acid oxidation, had no effect, thus supporting the enzymatic nature of the heme stimulation. Also, added bovine serum albumin did not stimulate the enzyme, indicating that protein probably did not exert any nonspecific stimulatory effects.

The mechanism of cyclooxygenase stimulation by protoheme compounds may be due to conversion of the apoenzyme to a holoenzyme. A previous experiment had shown that a significant amount of heme could bind to cyclooxygenase as evidenced by a large Soret peak (7) of a heme-supplemented preparation compared to the spectrum of the apoenzyme which had only a trace peak at $412 \mathrm{~nm}$. In order to more closely investigate this phenomenon, and to determine how much heme must be bound to the enzyme to attain maximal activity, purified enzyme samples were preincubated with different levels of added hematin and chromatographed to remove the free hematin.

The heme bound per 70,000 dalton subunit in three different unsupplemented preparations 
TABLE 1

Heme and Non-heme Iron in Cyclooxygenase ${ }^{a}$

\begin{tabular}{cccccc}
\hline Sample & $\begin{array}{c}\text { Heme/70,000 } \\
\text { daltons }\end{array}$ & $\begin{array}{c}\text { Absorbance } \\
\text { maximum (mm) }\end{array}$ & $\begin{array}{c}\text { Specific } \\
\text { activity } \\
\text { units/mg }\end{array}$ & $\begin{array}{c}\text { Stimulation } \\
\text { by heme }\end{array}$ & $\begin{array}{c}\text { Non-heme } \\
\text { Fe/70,000 } \\
\text { daltons }\end{array}$ \\
\hline 1 & $<0.01$ & 412 & - & - & 0.63 \\
2 & 0.05 & 412 & 5,143 & 7.7 & 0.81 \\
3 & $0.11^{b}$ & 412 & 14,375 & 3.2 & $0.57^{b}$ \\
4 & 0.49 & 412 & 18,100 & 1 & 0.75 \\
5 & 1.50 & 409 & 17,250 & 0.8 & 0.37 \\
6 & 2.89 & 406 & 13,750 & 0.8 & 0.42 \\
\hline
\end{tabular}

aPurified unsupplemented enzyme fractions in row 1 and 2 were obtained from Biogel P-30 gel filtration experiments, and the enzyme fraction in row 3 was obtained from a G-200 column. Hemesupplemented enzyme fractions (rows 4, 5, and 6) were obtained as described in Methods. Oxidized spectra, total iron, heme concentrations, and specific activities were obtained as described in Methods. Non-heme iron levels per 70,000 daltons were calculated as total iron minus heme iron. Specific activity measurements were based on standard assay conditions without added heme. The heme stimulation is expressed as the ratio of activity obtained when heme was included in the enzyme assay mixture divided by the activity in the absence of added heme.

$b_{C a l c u l a t i o n}$ of heme concentration for this enzyme fraction was based on an empirically derived average extinction coefficient $\left(\epsilon_{412}=205 \mathrm{mM}\right)$ for oxidized spectra.

TABLE II

Copurification of Non-heme Iron and Cyclooxygenase Activity ${ }^{a}$

\begin{tabular}{|c|c|c|c|c|c|c|}
\hline \multirow{2}{*}{$\begin{array}{l}\text { Purification } \\
\text { stage }\end{array}$} & \multirow{2}{*}{$\begin{array}{l}\text { Protein } \\
\mathrm{mg} / \mathrm{ml}\end{array}$} & \multirow{2}{*}{$\begin{array}{l}\text { Units/mg } \\
\text { protein }\end{array}$} & \multicolumn{2}{|c|}{ Total iron } & \multicolumn{2}{|c|}{ Heme } \\
\hline & & & $\mathrm{ng} / \mathrm{ml}$ & nmole/mg & $\mu \mathrm{M}$ & nmole/mg \\
\hline I-DEAE-cellulose & 0.40 & 12,500 & 80 & 3.6 & $0.13^{b}$ & $0.3^{b}$ \\
\hline II-G-200 & 0.46 & 46,000 & 250 & 9.7 & $0.71^{b}$ & $1.5^{b}$ \\
\hline III-P-30 & 0.07 & 26,800 & 36 & 9.2 & $<0.07 \mathrm{c}$ & $<1.0^{c}$ \\
\hline
\end{tabular}

aDEAE-cellulose data were taken from tube 56 Rome and Lands (10), Figures 2 and 3, and Table III. G-200 and P-30 enzyme fractions are the same as those in Table I, row 3 and row 1, respectively.

b Heme concentrations were calculated using $\epsilon_{412}=205 \mathrm{mM}$.

cHeme concentrations was determined from the reduced pyridine hemochrome, as described in Methods.

was 0.11 or less (Table I; samples 1,2,3). Analysis of the supplemented samples (4-6) showed that varied amounts of the added heme also may be bound. The preparations with low heme content (samples $1,2,3$ ) were stimulated when assayed in the presence of protoheme compounds (as predicted from Fig. 3). On the other hand, the apparently "heme-saturated" samples (4-6) were not stimulated. Thus, it appears that 0.5 heme $/ 70,000$ daltons may be the minimum amount of that prosthetic group necessary to give optimal activity.

The maximum absorbance in the Soret region (column 3) was consistently at $412 \mathrm{~nm}$ when 0.5 or less heme was present per 70,000 dalton subunit. The high affinity of heme binding may be deduced from the absence of any shoulder at $370 \mathrm{~nm}$ that could be attributed to free heme. However, as more heme was bound to the enzyme, the optimum absorbance shifted to $409 \mathrm{~nm}$ (1.5 heme/subunit) and to $406 \mathrm{~nm}$ (2.9 heme/subunit). In the latter sample, a shoulder in the $370 \mathrm{~nm}$ region indicated that some loosely bound heme had dissociated to the free form. Apparently the absorbance peaks at 409 and 406 were due to heme binding at site(s) of lower affinity that are not essential for an enzyme which was already $100 \%$ active.

\section{Presence of Non-heme Iron}

Besides heme-iron, purified cyclooxygenase contains significant non-heme iron, and thus resembles another fatty acid dioxygenase, soybean lipoxygenase, which has also been shown to contain non-heme iron (14). Further evidence supporting the presence of non-heme iron is indicated by the copurification of nonheme iron and enzyme activity as shown in Table II. Rome and Lands (10), using partically purified enzyme, obtained the data shown in 
row I. Our modified purification procedure, including additional steps (isoelectric focusing and gel chromtography), resulted in apparently homogenous enzyme preparations. The analyses for these preparations (II and III) show an increase in levels of iron $/ \mathrm{mg}$ and activity $/ \mathrm{mg}$ when compared to the cruder preparation. The lack of significant change in the apparent heme content per $\mathrm{mg}$ reinforces the concept that nonheme iron has co-purified with cyclooxygenase.

In order to quantitate the amount of nonheme iron in the various cyclooxygenase fractions listed in Table I, they were each assayed for total iron using flameless atomic absorption spectrometry, and the amount of heme iron was subtracted. The last column in Table I shows that a relatively constant amount of nonheme iron per 70,000 dalton subunit was obtained for each sample. There was some variability, but the average number of non-heme atoms per 70,000 daltons appears to be about 0.6. While further studies of the heme and nonheme iron stoichiometry are in progress, these preliminary numbers of 0.5 heme per subunit and 0.6 non-heme iron per subunit lead to an interesting theory. Perhaps there are two different kinds of subunits of 70,000 molecular weight, one which contains non-heme iron, and the other which binds heme. The tetrameric holoenzyme would then have an $\mathrm{A}_{2} \mathrm{~B}_{2}$-type of arrangement. The combintation of heme and non-heme iron in one enzyme has no known precedent. However, the cyclooxygenase reaction appears to include two dioxygenase steps. One may be analagous to the reaction catalyzed by lipoxygenase, an enzyme containing nonheme iron (14), and there may be a hememediated reaction analogous to tryptophan oxygenase catalysis. The latter enzyme has two types of subunits of similar molecular weight (15) and half of the subunits appear to bind heme. Tryptophan and indoleamine oxygenase enzymes were recognized as the only heme proteins known to catalyze the dioxygenase type of reaction $(16,17)$. Cyclooxygenase now represents a second type of dioxygenase activity that requires heme for catalysis.

With the purification and preliminary characterization reported here, the door is now open for mechanistic and regulatory insights. For example, the requirement for heme to con- vert the apoenzyme into a holoenzyme suggests that heme might have a very important physiological regulatory role in prostaglandin biosynthesis. Perhaps the heme must be available to the membrane-bound apoenzyme in order to convert it to the active form, and agents which would interfere with heme synthesis, availability, or binding could regulate prostaglandin synthesis.

\section{ACKNOWLEDGMENTS}

This work was supported in part by a grant from the National Science Foundation (BMS71-00906) and an Upjohn Graduate Fellowship (M.E.H.) from the Upjohn Co.

\section{REFERENCES}

1. Cook, H.W. and W.E.M. Lands, Biochem. Biophys. Res. Commun. 65:464 (1975).

2. Smith, W.L., and W.E.M. Lands, Biochemistry $11: 3276$ (1972).

3. Cook, H.W., and W.E.M. Lands, Nature 260:630 (1976).

4. Rome, L.H., and W.E.M. Lands, Proc. Nat. Acad. Sci. U.S.A. 72:4862 (1975).

5. Lands, W.E.M., H.W. Cook, and L.H. Rome in "Advances in Prostaglandin and Thromboxane Research," Vol. I, Edited by B. Samuelsson and R. Paoletti, Raven Press, New York, NY 1976, p. 7.

6. Smith, W.L., Prostaglandins 10:983 (1975).

7. Hemler, M., W.E.M. Lands, and W.L. Smith, J. Biol. Chem. $251: 5575$ (1976).

8. Lowry, O.H., N.J. Rosebrough, A.L. Farr, and R.J. Randall, J. Biol. Chem. 193:265 (1953).

9. Falk, J.E., "Porphyrins and Metalloporphyrins," Elsevier Publishing Co., New York, NY, 1965, p. $181,240$.

10. Rome, L.H., and W.E.M. Lands, Prostaglandins 10:813 (1975).

11. Smith, W.L., Prostaglandins (In Press).

12. Miyamoto, T., N. Ogino, S. Yamamoto, and $O$. Hayaishi, J. Biol. Chem. 251 : 2629 (1976).

13. Yoshimoto, A., I. Hiroyuki, and T. Kenkichi, J. Biochem. 68:487 (1970).

14. Rosa, M., and A. Francke, Biochim. Biophys. Acta 327:24 (1973).

15. Schutz, G., and P. Feigelson, J. Biol. Chem. 247:5327 (1972).

16. Feigelson, P., and F.O. Brady, in "Molecular Mechanisms of Oxygen Activation," Edited by 0 . Hayaishi, Academic Press, New York, NY, 1974, p. 87.

17. Hirata, F., and O. Hayaishi, J. Biol. Chem. 250:5960 (1975).

[Received January 17, 1977] 